\title{
Adapting Elementary School Curriculum Innovation in Line By 4IR and Cultures
}

\author{
Endang Setyaningsih \\ Department of Education and Culture \\ Pagerwojo 03 Elementary School \\ Blitar, Indonesia \\ endangsetya34@gmail.com
}

\begin{abstract}
Technology transformations in the Fourth Industrial Revolution encourage Indonesian elementary school education institutions to prepare the student with the modern ability to facing 4IR challenges. The revising of Indonesian elementary school curriculum must be implementing immediately to organize Indonesian young generation to compete in industrial networking and cultural degradations. Based on ASEAN Regional Education Networks publishing countering job losses and disruption from the 4IR impact will require a transformation of education. This research conducted to find out an important part of the elementary school curriculum that must revise to strengthen the student with $21^{\text {st }}$ century skills to increase the student competitiveness to face the global economy and abstract challenges in the 4IR era. This research employed qualitative content data analysis. It running by collecting data, recognizing, coding, mapping, interpreting and make some conclusion at the last of discussion. Based on this research resulted if the elementary school curriculum urgently to revise. There are eight find out suggestion to insert to adapting elementary school curriculum for facing job trend in $21^{\text {st }}$ century without prejudice to the preservation of Indonesian native cultures. Curriculum revise expected to increase optimism for Indonesian smart young generation to be aware to compete with technology and be wise to the native culture identity.
\end{abstract}

Keywords: curriculum innovations, education 4.0, elementary school curriculum, culture adaptation

\section{INTRODUCTION}

Elementary school curriculum innovation in disruptive technology is rapidly growing to the core of need. The changing of Indonesian curriculum in line by industrial network and culture adaptation must be implementing immediately to facing the global digital technology progress. Digital technology is fast becoming the core of life, work, culture and identity in Indonesia. In 2016, Indonesia had 76 million Facebook users, the fourth highest number in the world [1]. Jakarta has been called by the world's 'most active city on twitter'. It does not only influence the adult digital media user, but based from the research here a significant portion of the users are the elementary school student until after graduate age.

Digital technology had a marked impact on the media industry, informal sector employment, city panning, disaster relief, health, educations, religion and cultural expressions in the Industrial revolutions. The Indonesian elementary school education institution immediately renew itself to welcoming the rapid digital era and Internet of Thing (IoT) to preparing millennial generation under thirteen years old with $21^{\text {st }}$ century skills to compete in Fourth Industrial Revolution (4IR).

Industrial revolution 4.0 is currently a prevalent term. The revolution was initiated by the advancement of technology in many aspect of life. Moreover, industrial revolution 4.0 is related to digital technology which humans are being gradually replaced by technology-based practices [2]. Likewise with the native cultures, culture and local content will reduce by modernization and vanished without adaptation with technology.

McKinsey states that 52.6 million types of existing jobs will be substituted by technology-based practices as the result of industrial revolution 4.0. Humans, in the sense, may no longer have jobs as everything is run digitally. To cope with the situation, humans are required to equip themselves with highly refined skills and be mentally strong [3].

The competitiveness hinges on the basic education transformation to responding to industrial network and automations trend lies on curriculum adaptation. Curriculum adaptations in elementary school as an implementation of learning revolution have important effects on student's professional skills. To making a good synergy with the fourth industrial revolution $(41 \mathrm{R})$, the government is recommended to implement new curriculum to develop new competencies for the automation workforce. Information Technology (IT) lays the foundations for the core 4IRrelevant emerging technologies (big data, internet of things, and artificial intelligence). Indonesian government has developed new IT application for elementary school curriculum revise to prepare students for the 4IR challenges [4].

A new mindset that must be understood to cope the industrial revolution challenges in elementary school is the prevention of cultural and nationalism degradation for the Indonesian child. Nationalism, local content of culture very important to be integrates to the elementary school modern learning and digital education technology. Student's native culture adapt with making sustainability of new culture learning in the modern ways. New culture learning that adapt with IoT and Artificial Intelligence whose did not to refuse to evolved.

Y Jung at A New Culture of Learning: Cultivating the Imagination for a World of Constant Change resulted:

A new form of culture in which knowledge is seen as fluid and evolving, the personal is both enhanced and refined in relation to the collective, and the ability to manage, negotiate and participate in the world is governed by the play of the imagination. Replete with stories, this is a book 
that looks at the challenges that our education and learning environments face in a fresh way. PRAISE FOR A NEW CULTURE OF LEARNING. A provocative and extremely important new paradigm of a 'culture of learning', appropriate for a world characterized by continual change.

Y Jung also state if Cathy Davidson, Professor of Interdisciplinary Studies, Duke University says a new culture of Learning may provide for the digital media and learning movement. Then he also reviewing if Howard Gardner, Professor, Harvard Graduate School of Education "Thomas and Brown make it clear that education is too often a mechanistic, solo activity delivered to the young. It doesn't have to be that way-learning can be a messy, social, playful, embedded, constant activity [5]

Further in another result explained, the development of information technology encourages the occurrence of socio cultural perspective on the youth generation. It will be influence more revealing the diverse cultures around the world. The response sets performed by various cultures, especially on millennial segmentation. Serious problems in multicultural countries like Indonesia trigger cultural degradation and endanger cultural sustainability.

Nancy Duxbury in [6] was explained; The World Bank joined UNESCO in promoting culture in sustainable development (World Bank/UNESCO, 1998). Nonetheless, as Kavaliku noted,

The interrelationship between culture and sustainable development seems to be a matter of common sense. However, even though the United Nation (UN) system (and especially UNESCO) is pushing for recognition of it, the UN system has not in fact been very supportive. If we study the major global conferences of the 1990s-from Rio de Janeiro to Barbados, Cairo, Beijing, Copenhagen and Harare-their plans of action were concerned with sustainable development, but there was hardly a mention, even in dispatches, of culture.

According to these results above shows that the cultural developments influence the culture sustainability, and the gap between culture and sustainable development will to be a matter especially for Indonesian young generation or millennial. The UN as a cultural sustainability promoting agent very support and concern with cultural development and promoting it in global community including to Indonesia by education and cultural promotion to educate young generation to be nation culture savior.

Indonesian young generations as a culture savior have positive characteristic such as creative and innovative, but in another side they are materialistic, consumptive and tend to fell very prestigious imitate the culture of another nation. Based on the research conducted by elementary school teacher in elementary school in Indonesia know if the most of the children in the elementary school age (seven until 13 years old) do not recognized to their local culture. They more recognize to Korean, Japanese, Malaysian and American culture. BTS, Tayo, Pororo, Upin Ipin, Japanese anime, and Disney cartoon character more attractive than Indonesian traditional puppet "wayang”, Si Juki, Adit Sopo Jarwo and Indonesian traditional dance.

Furthermore the majority of Indonesian elementary school student not use the mother language well and not able to practice their native culture subject such as practicing traditional dance or traditional theatre. Most of them are refuse to learning local content subject and prefer to learn English languages. They feel that native culture making bored and unattractive to learn. Indonesian children more recognized to foreign cultures that they have adapted from You-Tube channel, social media and other online website. Even though You-tube channel, Whatsaap, Line, Facebook and other social media as informational technology development have bad impact of character to Indonesian young generation.

Free style, hedonist, individualistic, threads of nationality and pragmatic will to be the bad impact of character and behavioral change as the effect of information technology development. Here are the main reasons for Indonesian elementary school curriculum revise has becomes. Curriculum revise and adaptation with incorporating more Indonesian local culture content, nationalism and the national unity become the urgent project for the educational institution to preserve the native culture in the Fourth industrial revolution. Indonesian culture and social content in modern learning can be set to be attractive to children through the Augment Reality (AR) and Virtual Reality (VR) tools. Culture preservation must be encouraged in 4IR era by adapting the cultures with the technology development in Indonesian elementary school.

\section{METHOD}

\section{A. Qualitative Approach}

This research employed qualitative approach with data content analysis. The first step author collecting data from observation about curriculum and the competitiveness to facing 4IR revolution in elementary school, then organized the topic by recognizing, coding and mapping data from recording important reference and literature, resulting the literature review, interpreting. Hsiu Fang and Sarah mentioned qualitative content analysis is defined as a research method for the subjective interpretation of the content of text data through the systematic classification process of coding and identifying themes or patterns [7].

The author running this research using qualitative approach as an inquiry process to understanding and explore teacher and student problem in order to adapting the curriculum with the 4IR challenges and cultural degradation. The additional information correlate with the author research methodology Jhon W. Creswell explained on his result if qualitative research is an inquiry process of understanding based on distinct methodological traditions of inquiry that explore a social or human problem. The research builds complex holistic picture, analysis words, report detailed informant, views, and conduct the study in a natural setting [9].

The next step author collecting some data by making phenomenology observations, in depth interviews with elementary school teacher and make a focus group in the elementary school student to absorbing the valid data about urgently of curriculum revise by adapting to 4IR and native culture in real situation in Indonesian elementary school. Further author extended to compare the characteristic similar to that study from open access journal and online article 
content. Hsiu Fang and Sarah explained qualitative content analysis is one of research methods used to analyze text data. Other methods include ethnography, grounded theory, phenomenology, and historical research.

Further to completing this research the author make some literature review from twenty four research content from open access journal. It is in education, science, technology, computing, language and cultural international journal scope from Research Gate, Google Scholar, Elsevier, Science Direct, Atlantis Press, and other publisher. Beside that there are also review five educations article on Google page to completing this study. All the content organized by Mendeley Desktop literature libraries to make a citation. This is in accordance with Rahman $\mathrm{R}$. broad category of qualitative analysis is content analysis. The data for content analysis can take almost any form, including all types of written documents magazines, court proceedings, teacher's evaluations of students and audio or visual materials such as movies, television and advertisements [8].

Based on these methodology above Hsiu Fang and Sarah also mentioned; it was focuses on the real they noted, research using qualitative content analysis focuses on the characteristics of language as communication with attention to the content or contextual meaning of the text. Text data might be in verbal, print, or electronic form and might have been obtained from narrative responses, open-ended survey questions, interviews, focus groups, observations, or print media such as articles, books, or manuals [7].

For the goal of qualitative content analysis author coding to make some assumption that give the content meaning of the literature review, B. Kawulich explained, qualitative content analysis is to examine tasted, both the manifest content of an item, what is actually recorded or depicted, and the latent content. Latent content refers to the subtle messages or meaning encoded in an item, such as the unspoken assumptions that give the content meaning in the social world [10].

From raw data author make some evaluating data by recognizing and coding it, mapping and describing the patterns. In order to data processing author does not using mathematical calculation but it is interpreting data and provide their underlying meaning. After underlying the meaning the author make some conclusion at the last of discussion by suggesting some curriculum revise in line with modern technology and culture internalization. Rahman R. in [8] also mentioned that qualitative approach means an approach in which data processing does not involve mathematical and statistical calculations but emphasizes interpretative studies.

\section{B. Data Analysis}

In this research author involved literatures review types. Rahman R. explained, literature review is an activities relating to the method of collecting research materials from various literatures without requiring field research [8]. Based from this result author has been collecting some literatures and making review about main topic of research, discussing it and making some conclusion at least.

This research produces scientific reasoning ideas from the result of literature review and the results of the researches views about topic of research [8]. Author examines elementary school curriculum adaptation in line with Fourth Industrial Revolution (4IR) and culture. The technique of collecting data in this research used document analysis. Document analyzed in this research consist of research journals, literature journals, and seminar reports and online report. On the other hand, researcher collected data by reading, organizing topics, and recording important information on references.

\section{RESULTS AND DISCUSSION}

The fourth Industrial revolutions also call for a new way of formulating policy and regulation. The speed of change under the revolution is accelerating, and the old ways of crafting policy, especially cross-border policy are too slow to backward looking and too rigid. Instead, governance and regulation need to become more agile, faster, more iterative and experimental [11].

Various important things are fundamental to reform in Indonesian education and culture system especially for elementary school. Some thinking pattern must be adapt and acculturate in the basic of thinking and reference based from this research. We have suggested eight necessary points that must be implant to reforming Indonesian global curriculum in line by 4IR and cultures adaptation. These contents must be contained in the implications of new global curriculum suggested to implement to align with 4 IR era.

\section{A. ASEAN Education Network}

Fourth Industrial Revolution make the need for regional cooperation is increased. And the benefits that flow from deep regional collaboration, is significantly heightened. Indeed it is well documented that the fourth Industrial revolutions does not recognize national borders. The following exam show how a regional approach to addressing the fourth industrial revolutions will help ASEAN both capture the opportunities and manage the risk [11].

The Publications of Word Economic Forum (2017) state there are nine important point regional cooperation within ASEAN capture the opportunities and address the challenges of Fourth Industrial Revolution. It is (1) data sharing, (2) trade and manufacturing, (3) service standards (4) harmonized business environment, (5) rethinking fiscal policy (6) reducing barriers to labor mobility , (7) support a regional "human cloud" (8) regional educations networks, (9) innovative incubators. All of the result review on ASEAN 4.0 page: What does the Fourth Industrial Revolution mean for regional economic integration?

According to the page of World Economic Forum 2017 explained, ASEAN Regional Education Networks countering job losses and disruption from the Fourth Industrial Revolution will require a transformation of education. The skills need to thrive well center not only on technical capabilities but also on creativity and innovative problem solving. What's more given the accelerating pace of change in the job market, workers must except to have several careers rather than just one, which calls for a deep commitment to adult training and lifelong learning. Not just early-life education [11]. 
Furthermore based on the pages also explained, much of the response from policy-maker will play out at the national level. There is an important regional dimension too. Online education will give students access to education opportunities beyond their borders. Equally, the expansion of existing credit-transfer system between ASEAN universities would help build cross-border personal and professional networks, which will be crucial for the worker of tomorrow [11].

\section{B. Global Classroom by Cross-Cultural Collaboration}

Regional education networks as main part of educational sustainability preconditions must be implementing to reform the education platform as fourth industrial revolution effect. A. Wiek states in [3] during the academic year 2009/2010, an international group of fellows in residence at the Institute for Advanced Studies in Berlin (Wissenschaftskolleg zu Berlin) formed a working group on curriculum reformation. These fellows represented a wide range of disciplines (from physics and biology to political science and art history) and geographical regions (US, Europe, India, and Israel).

The global education research group produced a manifesto and a set of the central recommendation was to prepare students from the beginning of their studies to understand and deal with real-life problems at a global scale and to understand contextual (geographical, cultural) dimensions of knowledge [3]. Furthermore, maintaining global education sustainability by redesign curriculum advised to global classroom by adapting, (1) Virtual Collaboration, (2) Cross-Disciplinary and Cross-Cultural Collaboration.

Beyond the intangible issues of Virtual Collaboration, Arnim Wiek et al also state there are the invariable rules of using technologies in the classroom. If the teachers need to use it, and entire meeting revolves around the need of a technology to work correctly, it will fail sometimes (we have empirical evidence). Institutional technology support (technician), patient students, and good humored instructors are instrumental in surmounting such technical hiccups [3].

For an explained Cross-Disciplinary and Cross-Cultural Collaboration, Arnim Wiek mentioned, the global classroom seeks to equip students with tools and experiences on working in interdisciplinary, cross-cultural teams. The same applies to the instructors, often experience first-hand the need for patience, broad perspectives, and flexibility when it comes to attempting to globalize the educational landscape. Different epistemological perspectives manifest in the approaches take to planning Global Classroom activities [11].

In response, the teacher of global classroom are learning to practice the very process checks they teach to their students about successful international collaboration; listen to colleague perspectives, respect the work being done, question assumptions about differences in approaches, and communicate questions appropriately, and institute regular assessment of team interactions [3].

\section{C. $21^{\text {st }}$ Century Skills Frame Work}

McKinsay Global Institute explained, the disruption to the world of work that digital technologies are likely to entail could pose significant challenges to both of policy makers and business leaders, as well as workers. Then they recommend several solution spaces to consider one of them is to evolve education systems for a changed workplace. Policy makers working with education providers (traditional and non-traditional) could do more to improve basic STEM skills through the school systems, and put a new emphasis on creativity as well as critical and systems thinking [12].

It expected that all millennial education output have been equipped with creative abilities to meet life's challenges in the 21st century. Carles Fadel [13] review Time Magazine published a quote about the way to build the student for the 21 st century skills,

This is a story about whether an entire generation of kids will fail to make the grade in the global economy because they can't think their way through abstract problems, work in teams, distinguish good information from bad, or speak a language other than (their own).

Furthermore Carles Fadel [13] states, there are three main of skills that must to develop by student to welcome $21 \mathrm{st}$ century, First is Life and Career Skills, (1)Flexibility and Adaptability. (2) Initiative and Self-Direction. (3) Social and Cross-Cultural skills. The Second skill is Learning and Innovations (1) Critical Thinking and problem Solving. (2) Creativity and innovation. (3) Communication and Collaboration. The last skill is Information, Media and Technology covers: (1) Information Literacy. (2) Media Literacy. (3) Information, Communications and Technology (ICT) Literacy.

S. Kwek has published his research result in an American public middle school in 2011. We can adapt this research result to reform the content of 4 IR curricula in our elementary school. S. Kwek explained, the research with te participants for the study are the school leader and teachers from a public middle school in the San Francisco Bay Area. Based from the research show through lesson observations and interviews, his study aims to develop a fuller understanding of the motivations that drive teachers to adopt this innovative approach and the considerations they have when using it in the teaching and learning of core content [14].

Then S. Kwek also findings shows that the teachers were not passive recipients of this new pedagogical tool and have "appropriated" it in multiple unique ways - to suit different purposes, different learning contexts and their different subjects. Another key finding is that mastery of academic core content still drives how design thinking is used to intersect with classroom learning. From his study S. Kwek emphasizes the need to promote 21 st century skills and academic content knowledge as similarly important student outcomes. The cultivation of a broader set of skills and dispositions beyond core content knowledge is critical, and they merit the investment of more time in the classroom [14].

\section{Automation and Cultural Adaptation}

Automation in various sectors of life is very urgent to be done as result of rapidly technology development and the requirement of efficiency in the industrial and trade sectors. McKinsey has mentioned, the development of automation enabled by technologies including robotics and artificial 
intelligence brings the promise of higher productivity, increased efficiencies, safety, and convenience, but these technologies also raise difficult questions about the broader impact of automation on jobs, skills, wages, and the nature of work itself. Many activities that workers carry out today have the potential to be automated [12].

\section{Publish in the result McKinsey also noted,}

Automation out breaking in various sectors has forced some adaptation of education curriculum by some automation. The educational institution today must be ready to produce the education output with more than one expertise and have the resilience to the shock of global problems. It needed to compete and ready to be entrepreneurs output, that able to be self-employer, not only to be enterprise job seekers. Besides that, the young generations must be adapting cultural change and liberation as consequence of global challenges.

Further to facing this challenge, the entire education system must prepare their graduates who ready to changing nature of work early and have some skills to produce work. As McKinsey said, in their result explained if educational systems have not kept pace with the changing nature of work, resulting in many employers saying they cannot find enough workers with the skills they need. In a McKinsey survey of young people and employers in nine countries, 40 percent of employers said lack of skills was the main reason for entry-level job vacancies [12].

According to related result McKinsey also mentioned, sixty percent of new graduates were not adequately prepared for the world of work. There were gaps in technical skills such as STEM subject degrees, but also soft skills such as communication, team work, and punctuality. Conversely, even those in work may not be realizing their potential. In a recent global survey of job seekers conducted by LinkedIn, 37 percent of respondents said their current job does not fully utilize their skills or provide enough challenge [12].

In another result, H.C.Y. Chan in [15] mentioned about the necessary of automation in classroom in 4IR. He was said, classrooms can be augmented with computer-generated stimulus that appear in reality, namely augmented reality (AR) through their smartphone cameras. AR merges reality with fake stimuli to enhance learning; data appear over reality so student can observe artificial images in a realworld setting. There are currently AR apps for almost any subject, such as geometry, translation, math, and art. For insurance, user of the free Google translate app can translate text into other languages in real-time by capturing the text on their smartphone [15].

H.C.Y Chan also explained, together, digitally augmented classroom strengthen learning capacity, happiness, and competitiveness of universities. Admittedly, incorporating these technologies is costly and time intensive but the investment brings long-term benefits. Traditional classroom can be replaced by online courses, but augmented classroom cannot be. While augmenting digital classroom is one way smart campus can assists education, smart campuses enhance learning in other ways as well [15].

Automation and augmentation in the digital classroom give some impact on the native culture sustainability as similar with the human culture adaptation. Rooted in detailed case studies of cities in Nepal, Malaysia, Korea, and Japan about culture adaptation, Nancy Duxbury and M. Sharone review some literature at [6] mention four alternate approaches towards "culturally sensitive sustainable urbanism and modernization" were put forward:

1. Internal cultural transformation - Based on 1500 years of urban history and cultural practices in Patan, Nepal. It defined sustainability as a dialogical equilibrium maintained in three sets of relationships: between man and economy (economic pursuits), between man and man (social heterogeneity); and between man and nature (environment and ecology). Culture is the active process that balances these relationships to achieve sustainability [6].

2. Multiculturalism and enlightened localism - Based on reviewing an examination of planning and socio-cultural challenges in Penang, Malaysia articulated eight integrated principles to guide sustainable and culturally informed citybuilding, giving prominence to multicultural diversity and "enlightened localism" as pathways towards sustainable cultures..

3. Urban cultural identity In light of cultural identity challenges in the rapidly growing city of Cheongju, Korea, concluded that the "urban cultural system" is not sufficient to bring about a culturally sensitive sustainable. Thus, he placed his focus on integrating culture within five sectorial/functional systems or domains of action: governance, economy, environment, spatio-physical (urban structure and development patterns), and societal systems.

4. Cultural mode of production In the pursuit of a "true globalization with harmony and moderation," Sasaki's study of Kanazawa, Japan, focused on the operationalization of local distinctiveness through a new "global yet varied" social and production system model. From a sustainable city perspective, three decisive factors were: (1) unique character and specialties, based on a city's traditions and culture; (2) creativity and the ability to adjust to new circumstances; and (3) cooperation between residents and the local government.

Katriina Soini and Joost Dessein explained about culture shock from difference,

Immersion in a foreign culture, while initially exciting, often leads to a state of emotional distress. This personal disequilibrium, brought about by encountering unexpected or disturbing differences of behavior and social expectations, and by difficulties in communication, has been termed "culture shock" a designation introduced in 1950 by Kalervo Oberg. Symptoms of distress may become intense, and may even lead to psychological problems [16].

But in general culture shock is mastered by a process of adaptation to the new culture. Indeed, it may be considered a regular part of learning a culture and information technology development influence. Cultural savior, surprisingly, experience equal or even greater disorientation on return to their own culture, a condition which shows the depth of personality transformation that is brought about by adapting to a new culture [16].

Rais Rahayu S.N. resulted that the effect of global information can provide significant mindset changes for the millennial generation view-point. Therefore as the next nation generation and the nation culture savior the millennial 
need to be prepare their mind-set with appreciation and deep understanding of native cultures through education. Education institution should be implement the diversity native culture subject as a main point of curriculum content reviews as the effort to strengthening the nationalism and the preserve of socio-culture degradation could be minimized in fourth industrial revolution.

The curriculum review and adaptation with incorporating more local culture content, nationalism and the national unity issues become the urgent project for the educational institution todays. Curriculum adaptation by cultural content internalization takes the government's role to revise the strict rules and sanction of misuse of internet, making appropriate legal policies related to the technological advancement to be adaptable laws to prevent the cultural degradation.

\section{E. Smart Classroom Augmented}

Yuanchun Shi explained research result about smart classroom prototype that we can adapt to implemented on Elemnetary school 4IR curricula. They have explained in their result if smart classroom seamless tele-education systems. It promises wider access to education and support for lifelong learning. These systems are either asynchronized or synchronized. Asynchronized systems are relatively simple. An organization can use the Internet to publish hyperlinked multimedia content and reach a wide audience. Yet, most current courseware is simply textbook material transferred to HTML; instead of reading the book, students read the screen. In most cases, live instruction catches students' attention and interest much more effectively role in distance learning [17]

Yuanchun Shi also exemplifies the prototype of smart classroom design with a variety of sophisticate equipment that adapt to improving 4IR elementary school curriculum. They were noted, In the type of tele-education, multimedia communication systems let teachers and students in different locations participate in the class synchronously. Most systems are desktop based, however, so the teacher must remain at the computer. We use the keyboard and mouse to operate the class an awkward experience for a teacher. By applying smart space technologies in a real classroom, the Smart Classroom project bridges the gap between teleeducation and traditional classroom activities in terms of the teacher's experience and seamlessly integrates these two currently separate educational practices [17].

More specifically, we extend the user interface of a legacy desk tele-education system into the 3D space of an augmented classroom. In the Smart Classroom, teachers can use multiple natural modalities while interacting with remote students to achieve the same effect as a teacher in a classroom with local student [17].

Based on their result, Yuanchun Shi explained the advantages of automate classroom. They mentioned, the system turns a physical classroom into a natural user interface for tele-education software. Teachers in the Smart Classroom can move freely, using conventional teaching methods to instruct remote students. Because they are in a real classroom environment, they can accommodate local students at the same time. Simultaneously instructing local and remote students also requires a smaller workforce than separate on-campus and tele-education operations. Further- more, the lecture, recorded as hypermedia course- ware, is available for playback after class [17].

\section{F. Eight Technology for Youth Job Trend in 4IR}

Technology-based on the curriculum adaptation is the main project of student careers in the future. Nikita Duggal states,

The careers don't change at that same speed, but they do evolve, and the savvy IT professional recognizes that his or her role will not stay the same. The IT worker of the 21st century will constantly be learning, out of necessity if not desire. What does this mean for you? It means staying current with technology trends. And it means keeping your eyes on the future, to know which skills you'll need to know and what types of jobs you want to be qualified to do.

Further, Nikita mentioned eight technology trends should watch for in 2019, and some of the jobs that will be created by these trends (1) Artificial Intelligence (AI), (2) Machine Learning, (3) Robotic Process Automation (RPA), (4) Blockchain, (5) Edge Computing, (6) Virtual reality (VR) or Augmented Reality (AR), (7) Cyber Security, (8) Internet of thing (IoT).

\section{1) Artificial Intelligence (AI)}

Artificial Intelligence refers to computers systems built to mimic human intelligence and perform tasks such as recognition of images, speech or patterns, and decision making [25]. AI can do these tasks faster and more accurately than humans work. AI is already significantly impacting the way customers interact with businesses via intelligent websites and bots, and these tools are becoming increasingly commoditized and integrated into daily work, the report noted.

$\mathrm{AI}$ is a part of what we refer to broadly as automation, and automation has hot topic because of potential job losses. According to some expert said automation will eliminate 73 million more jobs by 2030 . However, automation is creating jobs as well as eliminating them, especially in the field of AI. Jobs will be created in development, programming, testing, support, and maintenance, to name a few. Artificial Intelligence architect is one such job. Some say it will soon rival data scientist in need for skilled professionals [25].

The consequence of AI for human being cannot be avoiding today, Alberto Pahecho reported that AI has been profoundly modifying daily lifestyle. Over the past 50 years, AI has developed logic-based systems, bio-inspired systems, collaborative agents, cyber-physical intelligent systems, and "ubiquitous AI" or pervasive intelligence systems. The great ability of Machine Learning (ML) - a subarea of AI - is to analyze large data flows. It has been popularized and consolidated during the last decade at all levels of research, industry and entertainment [18].

Curriculum innovation must be enclosing AI on the part of new curriculum content. Further to illustrate how to adapting $\mathrm{AI}$ on the education, author will review some result from Senior Program Leader AI for Education. Ellaine Garcia mentioned,

We are now moving into a new age of technology, one in which artificial intelligence (AI) or machine learning are being developed. Therefore, we need to once again consider 
whether such technology should be used within education and, if it should, how it will be useful in enhancing teaching and learning. Currently, there are a wide range of predictions of how AI will be integrated into future education.

Then Elliane Garcia noted the range from commentators predicting that AI will only take over the administrative tasks of teachers, to others who predict that AI will replace teachers within the classroom entirely. While such concepts may be hard to imagine for the majority of teachers, AI is already being used in some classrooms today. For example, IBM Watson, Third Space Learning and Duolingo Chatbot are all forms of AI already being used to enhance learners' experience.

What is of key importance, however, when considering the use of $\mathrm{AI}$ in education, is to once again ensure that it is pedagogy, rather than the technology that is driving the development of new and different approaches to education.

\section{2) Machine Learning}

SAS at Machine Learning What it is and why it is Matters mentioned, Machine Learning is a method of data analysis that automates analytical model building. It is a branch of artificial intelligence based on the idea that systems can learn from data, identify patterns and make decisions with minimal human intervention. Machine learning as well as deep learning, natural language processing and cognitive computing are driving innovations in identifying images, personalizing marketing campaigns, genomics, and navigating the self-driving car.

Machine Learning is a subset of AI. With Machine Learning, computers are programmed to learn to do something they are not programmed to do: They literally learn by discovering patterns and insights from data. In general, we have two types of learning, supervised and not supervise, reported by SAS.

Pedro Domingos explained, Machine Learning is rapidly being deployed in all kinds of industries, creating a huge demand for skilled professionals, data mining and pattern recognition. On the consumer end, Machine Learning powers web search results, real-time ads, and network intrusion detection, to name only a few of the many tasks it can do [19].

To implement machine learning, Alberto Pahceo designed smart classroom initial design goals including the machine learning. Smart technology were to build a lowcost, high responsive, and energy saving smart lighting system that can be scaled from a classroom level, up to a building or full campus level. Other functional requirements were a heterogeneous and distributed processing environment, real-time image processing, machine learning algorithms processing on diverse equipment and wireless control for IoT devices to provide a very flexible and responsive smart lighting module, and some other facilities as multimedia projection and door locking control [18].

\section{3) Robotic Process Automation or RPA}

Like AI and Machine Learning, Robotic Process Automation, or RPA, is another technology that is automating jobs. RPA is the use of software to automate business processes such as interpreting applications, processing transactions, dealing with data, and even replying to emails. RPA automates repetitive tasks that people used to do. These are not just the menial tasks of a low-paid worker: up to 45 percent of the activities we do can be automated, including the work of financial managers, doctors, and CEOs.

Sample of the implementation of RPA for adapted to 4IR curriculum has planned by Ali Durmus and Abdul Kadir in curriculum of Vocational School. They have mentioned in their result, Curriculums of Vocational Schools need to be re-audited so that they can keep pace with the rapidly changing industry conditions in recent years. Although protocols have been made for the development of laboratories within the scope of industry-university cooperation, the expected yield has not been obtained [20].

Minna Lanz has explained their research result about robotic education,

To support this specific major in Robotics was formalized. A student majoring on Robotics will achieve knowledge of and ability to analyze fundamental computational methods relevant to robotic manipulators and mobile robots, including modeling, planning, localization, and control, and experimentation on real robot platforms. The courses in this major in general train the student to use SW tools such as Robot Operating System (ROS), Matlab and Simulink. Regardless the selection of additional/complimentary courses, all of the participants will design and implement a simple robotic system including hardware and software solutions.

Minna lanz also describes the Tampere RoboLab offers a place for students to work with robotic equipment and experiment without major restrictions. Robots and related technology are for example industrial manipulators [21]. RPA must be entered to new curriculum adaptation to sustainability basic education in the future.

\section{4) Blockchain}

Nikita Duggal has explained about the importance of blockchain technology for easy data control and emerging employment opportunities for 2019 ,

Blockchain can be described as data you can only add to, not take away from or change. Hence the term "chain" because you're making a chain of data. Not being able to change the previous blocks is what makes it so secure. In addition, blockchains are consensus-driven, as explained in this Forbes article, so no one entity can take control of the data. With blockchain, you don't need a trusted third-party to oversee or validate transactions.

In another result Arshdeep Bahga resulted Blockchain is a distributed data structure comprising a chain of blocks. Blockchain acts as a distributed database or a global ledger which maintains records of all transactions on a Blockchain network. The transactions are time stamped and bundled into blocks where each block is identified by its cryptographic hash [22].

The blocks this heightened security is why blockchain is used for cryptocurrency, and why it can play a significant role in protecting information such as personal medical data. Blockchain could be used to drastically improve the global 
supply chain, as described here, as well as protect assets such as art and real estate. Jobs are available at financial institutions, but also in retail and healthcare, and soon probably manufacturing as well [23].

In another necessary result author will reviewing a sample of the result which applying the blockchain in European high school education. We must enter their reseach result to introducing blockchain technology in the elementary school curriculum reformation. M. Turkanović, in his research result mentioned,

Blockchain technology enables the creation of a decentralized environment where transactions and data are not under the control of any third party organization. Any transaction ever completed is recorded in a public ledger in a verifiable and permanent way. Based on blockchain technology, we propose a global higher education credit platform, named EduCTX. This platform is based on the concept of the European Credit Transfer and Accumulation System (ECTS). It constitutes a globally trusted, decentralized higher education credit and grading system that can offer a globally unified viewpoint for students and education institutions (HEIs), as well as for other potential stakeholders such as companies, institutions, and organizations.

Further M. Turkanovic states, as a proof of concept, we present a prototype implementation of the environment, based on the open-source Ark Blockchain Platform. Based on a globally distributed peer-to-peer network, EduCTX will process, manage and control ECTX tokens, which represent credits that students gain for completed courses such as ECTS. HEIs are the peers of the blockchain network [22].

For implementation of Blockchain, M. Turkanovic explained the step of implementation of this technology as follows; the platform is a first step towards a more transparent and technologically advanced form of higher education systems. The EduCTX platform represents the basis of the EduCTX initiative which anticipates that various HEIs would join forces in order to create a globally efficient, simplified and ubiquitous environment in order to avoid language and administrative barriers. Therefore we invite and encourage HEIs to join the EduCTX initiative and the EduCTX blockchain network [23].

\section{5) Edge Computing}

Nikita Duggal noted, Edge Computing. Formerly a technology trend to watch, cloud computing has become mainstream, with major players AWS (Amazon Web Services), Microsoft Azure and Google Cloud dominating the market. The adoption of cloud computing is still growing, as more and more businesses migrate to a cloud solution. But it's no longer the emerging technology. Edge is Move over; cloud computing, and make way for the edge.

Alberto Pacheco noted, Edge Computing Most IoT control actions must be carried out in real time, so cloud processing waiting time does not work well for IoT problems. Some recent and complementary paradigms that try to cover some of these limitations are Fog and Edge Computing, which claims to be capable of performing tasks in a more distributed and responsive way when IoT nodes are closer to the sensor data sources, also reducing network traffic and avoiding to expose user data and privacy [18].
Alberto also reviewing based from some literatures the sample of implementation edge computing that can be adapt to setting a smart classrooms as a curriculums innovation models in elementary school,

The Edge Computing paradigm is so new that it lacks a standard definition, architectures and protocols. Currently, there is a growing number of Edge Computing application in automation. Such as monitoring, control and security in embedded systems and industrial-type IoT ecosystems. Lighting, air conditioning and intelligent monitoring, analytical, energy saving, security for smart buildings; monitoring and remote assistance for patients, rehabilitation and elderly people; intelligent vehicles, assisted driving, V2X protocols, traffic monitoring and control; smart clothes, games, augmented reality and virtual reality, fitness and training are using edge computing [18].

Then Alberto also mentions the leading Edge Computing advantages. They are, reduction in latency and response time suitable for real-time applications; processing, filtering, compression and encryption of data flows; reduction of data traffic and storage; greater context and location sensitivity; achieve distributed cognitive processing; and better use of the computing and communication potential present in current mobile devices and IoT nodes[18].

Finally Alberto making some conclusions, among the main obstacles to perform data processing in these "edge" devices are, its limited energy capacity and As the quantity of data we're dealing with continues to increase, we've realized the shortcomings of cloud computing in some situations [18].

\section{6) Virtual Reality or Augmented Reality}

Virtual Reality (VR) immerses the user in an environment while Augment Reality (AR) enhances their environment. Although VR has primarily been used for gaming thus far, it has also been used for training, as with VirtualShip, simulation software used to train U.S. Navy, Army and Coast Guard ship captains. The popular Pokemon Go is an example of AR.

Both have enormous potential in training, entertainment, education, marketing, and even rehabilitation after an injury. Either could be used to train doctors to do surgery, offer museum-goers a deeper experience, enhance theme parks, or even enhance marketing, as with this Pepsi Max bus shelter. VR in education designed virtual classrooms. Virtual teaching learning have the drawback of requiring students from different countries to $\log$ in at a certain time, and time zone differences can pose a problem for flexibility [15].

Fortunately Hubert C. states, E-learning does not necessitate use of virtual classroom and e-learning still be free from time constraints. Instead of joining virtual classrooms, students and teachers can communicate via discussion boards, Emails, and recorded messages in their own time. This type of communication learning, termed asynchronous learning, occurs because the student and teacher are not necessarily online at the same time [15].

In these cases, computer-mediated communication (CMC) in asynchronous learning environments means students and teachers to communicate at different time intervals. While this permits flexibility for both parties, real- 
time face-to-face discussions are often faster, easier, and convenient. While CMC gives students more time to analyze content and students can learn at their own pace [15].

\section{7) Cyber Security}

Reviewing from various experts study about cyber security and concluded that cyber security evolving just as other technologies. That's in part because threats are constantly new. The malevolent hackers who are trying to illegally access data are not going to give up any time soon, and they will continue to find ways to get through even the toughest security measures.

Nikita Duggal explained, it's also in part because new technology is being adapted to enhance security. Three of those advancements are hardware authentication, cloud technology, and deep learning, according to one expert. Another adds data loss prevention and behavioral analytics to the list. As long as we have hackers, we will have cyber security as an emerging technology because it will constantly evolve to defend against those hackers.

Nick Walter states, most data breaches are the result of human error. A strong school network security regimen holds no great significance if students and staff don't understand how to mitigate risk. Therefore, introduce cybersecurity training for all staff and students who regularly make use of technology on school grounds. Such training may include: (1) How to identify safe and unsafe sites, (2) Spotting phishing attempts or other scams, (3) Using antiviruses, malware or another frontline defense, (4) Find the best in free firewalls.

Then Nick Walter also remind, by investing time and expenses in the actual training the mitigation strategy in place will be twice as more effective; if a risk does develop it will be more likely to receive an early detection and do-little damage once addressed. It is apparent that today no sector is immune from the threat of a cyber-attack and this sadly includes schools and universities. The voluminous data these institutions hold as well as the increasing number of connected devices makes this sector a vulnerable domain for cyber-hacking.

Nick Walter advice at great statement at least,

Given the complexity of networks today, and of the threats to their security, traditional anti-virus solutions are also no longer enough. Therefore, manually following the above best practices ensures you are covered as vicinity from all areas. Cyber security is no longer considered just an IT issue but is holistically approached throughout the organization and hence should be treated as a collaborative effort to mitigate.

\section{8) Internet of Thing (IoT)}

The IoT can enable better safety, efficiency, and decision making for businesses as data is collected and analyzed. It can enable predictive maintenance, speed up medical care, improve customer service, and offer benefits we haven't even imagined yet. However, despite this boon in the development and adoption of IoT, automation, understanding of embedded systems, device knowledge, to name only a few. After all, it's the Internet of Things, and those things are many and varied, meaning the skills needed are as well.
Alberto Pacheco designed smart IoT devices and smart classroom infrastructure. A complete wall was divided into two sections for a traditional chalkboard and an acrylic whiteboard. The vision-capture system supported two dedicated Logitech C170 webcams connected via USB 3.0 and operated simultaneously by the Ubuntu/NUC vision IoT microserver. The smart lighting module was implemented using a Philips Hue starter kit that contains 4 dimmable LED bulbs and one WiFi/ZigBee bridge handled directly by the Raspbian/RBP IoT microserver. Other IoT devices were controlled but not being described on this report, e.g. a wireless smart lock door and multimedia projector [18].

Alberto Pacheco designed smart classroom controlling application and DNN on-device inference testing. It used two different edge mobile devices: A smartphone model Alcatel Pixi 3 with a quad-core ARMv8 64-bit CPU @ $1.3 \mathrm{GHz}$ and 1GB RAM with Android 5.1; a 9.7-inch tablet model Apple iPad 6th-Gen (2018) with a quad-core A10 Fusion ARMv8 64-bit CPU @ 2.34GHz and 2GB RAM with iOS 12 Beta 2 [18].

\section{G. Digital Literacy for Elementary School Output}

Main aspect that must be reform from Indonesian elementary school curriculum is literate about digital technology and digital literacy. Every elementary school student must be able to operate digital technologies application especially internet, mobile phone and web to prepare some skills to develop properly in economic and employment opportunities. It called digital literacy based on education.

Amalia Rahmah in [24] states, digital literacy concept preparing citizen to be digitally literate and competent using ICT to support their learning process, doing their work more effective and efficient, and preparing Indonesian young generation to become qualified workforce competing in FTAAP 2020, furthermore international work competition. This is in line with the curriculum reformation to facing the education modernization.

Digital literacy as the implication of modernization of education expected to digital technology mastery for youth generation for new opportunities in economic productivity progress as a worker seekers in futures. McKinsey in [12] resulted,

Technologies are creating major new opportunities for workers and companies, in both advanced and developing economies, but there are significant variations within and across countries and sectors. The United States, for example, has a major opportunity to boost productivity growth from digitization: digitization in just three big areas-online talent platforms, big data analytics, and the Internet of Thingscould add up to $\$ 2.2$ trillion to annual GDP by 2025 , although the possibilities are much wider.

Further about the comparison degree of digitalization measured McKinsey mentioned if including health care, education, and even retail are much less digitized [12],

The degree of digitization can be measured in terms of assets, usage, and the extent to which jobs and work are enabled by it. Based on these measures, a few sectors are highly digitized, for example financial services, media, and the tech sector itself. These tend to be among the highest 
productivity growth and wage growth sectors. Many others are much less digitized, including health care, education, and even retail.

\section{H. Example 4IR Competencies to Develop 4IR curricula in Foreign Country}

Tran Thi Bich Lieu in [4] mentioned, in Vietnam most of the 57 4IR-related curricula review included separate IoT or big data or AI content, but lacked new specific or interdisciplinary curricula in these fields. Only Hanoi University of Science and Technology offered three elements of IoT, big data and AI in the curricula, but most were selective modules and for only talented students. The University of Information Technology at Vietnam National University in Hochiminh City (VNUHCM) provided CPSs, IoT, big data and AI related research topics, but only for doctoral degrees [4].

Furthermore Tran Thi Bich Lieu noted, similarly, Malaysia's Taylor University's bachelor of computer science had an embedded module on robot design as well as a minor in the existing curriculum. This curriculum included selected options in either IoT or big data. In both Vietnam and Malaysia emphasis was placed on AI, while big data and IoT were only marginally developed. $100 \%$ of the 57 Vietnamese curricula reviewed had AI content. Forty three of the reviewed curricula of 35 IT departments in Malaysia have AI covered, via both embedding and newly developed [4]

\section{CONCLUSION}

ASEAN Regional Education Networks countering job losses and disruption from the Fourth Industrial Revolution will require a transformation of elementary school education. Various important things are fundamental to reform in Indonesian education and culture system especially for elementary school. Some thinking pattern must be adapt and acculturate in the basic of thinking and reference based from this research.

The author have suggested eight find out suggestion to insert to adapting elementary school curriculum for facing job trend in 21st century without prejudice to the preservation of Indonesian native cultures. Here are necessary points that must be implant to reforming Indonesian global curriculum in line by 4IR and cultures adaptation. These contents must be contained in the implications of new Indonesian elementary school curriculum suggested to implemented to align with 4 IR era

The first content has suggested is transformation of education in elementary school. Elementary school teaching learning must teach the diversity skills not only on technical capabilities but also on creativity and innovative problem solving. Student must have much accelerate pace of change in the job market. They as workers must except to have several careers rather than just one. New roadmap elementary education allowed for a deep commitment to adult training and lifelong learning.

The second is new elementary school curriculum also allowed global classroom implementation. Global learning doing practice the process checks they teach to their millennial students about successful international collaboration by cross-cultural collaboration. It expected that all millennial education output have been equipped with creative abilities to meet life's challenges in the 21 st century.

The author suggesting three main of skills that must be implement to new elementary school curriculum to develop by student to welcome 21 st century, First is Life and Career Skills, (1)Flexibility and Adaptability. (2) Initiative and SelfDirection. (3) Social and Cross-Cultural skills. The Second skill is Learning and Innovations (1) Critical Thinking and problem Solving. (2) Creativity and innovation. (3) Communication and Collaboration. The last skill is Information, Media and Technology covers: (1) Information Literacy. (2) Media Literacy. (3) Information, Communications and Technology (ICT) Literacy.

The revise of curriculum author also suggest to implementing automation and augmentation in the digital classroom. It will give some impact on the native culture sustainability as similar with the human culture adaptation. Education institution should be implement the diversity native culture subject as a main point of curriculum content reviews as the effort to strengthening the nationalism and the preserve of socio-culture degradation could be minimized in fourth industrial revolution.

The next point Indonesian elementary school curriculum suggested to applying smart classroom seamless teleeducation systems. It promises wider access to education and support for lifelong learning. In the type of tele-education, multimedia communication systems let teachers and students in different locations participate in the class synchronously.

Technology-based on the elementary school curriculum adaptation also to be the main project revise to build up student careers in the future. There are mention eight technology trends should implement for Indonesian curriculum revise, and some of the jobs that will be create by these trends. (1) Artificial Intelligence (AI), (2) Machine Learning, (3) Robotic Process Automation (RPA), (4) Blockchain, (5) Edge Computing, (6) Virtual reality (VR) or Augmented Reality (AR), (7) Cyber Security, (8) Internet of thing (IoT)

Further digital literacy suggesting implementing in elementary school as the implication of modernization of education expected to implement in elementary school curriculum revise. Mastery of digital technology for the younger generation is a new opportunity in advancing economic productivity as a producer or job seeker in the future. The degree of digitization is measured in terms of assets, usage, and the extent to which jobs and work are enabled by it.

The last suggestion is to compare the implementation of 4IR curricula with the 4IR curricula in another country from basic education till after graduate. Vietnam most of the 57 4IR-related curricula review included separate IoT, big data and AI content in all their education institution. Similarly, Malaysia Taylor University bachelor of computer science had an embedded module on robot design as well as a minor in the existing curriculum. So, Indonesian Elementary school curriculum also needs to prepare to revise by Indonesian government to facing the 4IR challenges.

In conclusion the elementary school curriculum needs to revise immediately to strengthen the elementary school student competitiveness to facing 4IR challenges. 
Curriculum enclose smart system, smart classroom, digital literacy and creative learning to be accelerate the Indonesian child to be modern people with native cultures identity. Indonesian Elementary School learning innovation making optimism for smart young generation to be aware to compete and be wise to the native culture in disruptive era.

\section{ACKNOWLEDGMENT}

The authors acknowledge the contributions of several education supervisors from Blitar Department of Education and Culture, Family member of Pagerwojo 03 Elementary School and all supported. These professionals contribution motivate to complete this journal. The Authors gratefully acknowledge their support and assistance.

\section{REFERENCES}

[1] E. Jurriëns and R. Tapsell, "Challenges and opportunities of the digital 'revolution' in Indonesia," Digit. Indones. Connect. Divergence, vol. 2020, 2017, pp. 275-288.

[2] R. Rahman, A. W. Sakti, R. N. Widya, and R. Yugafiati, Elementary Education Literacy in the Era of Industrial Revolution 4.0, 2019.

[3] A. Wiek, M. J. Bernstein, M. Laubichler, G. Caniglia, B. Minteer, and D. J. Lang, "A Global Classroom for International Sustainability Education," Creat. Educ., vol. 4, Apr 2013, pp. 19-28.

[4] T. T. B. Lieu, N. H. Duc, N. W. Gleason, D. T. Hai, and N. D. Tam, "Approaches in Developing Undergraduate IT Engineering Curriculum for the Fourth Industrial Revolution in Malaysia and Vietnam,” Creat. Educ., vol. 9, 2018, pp. 2752-2772.

[5] Y. Jung, "A new culture of learning: cultivating the imagination for a world of constant change," Stud. Art Educ., 2015.

[6] N. Duxbury, M.S. Jeannotte, S. De, and Officina $\mathrm{N}^{\circ}$, "Culture, sustainability, and communities: exploring the myths," 2010 .

[7] H. F. Hsieh and S. E. Shannon, "Three approaches to qualitative content analysis," Qual. Health Res., vol. 15, 2005, pp. 1277-1288.

[8] R. Rahman, A. W. Sakti, R. N. Widya, and R. Yugafiati, Elementary education literacy in the era of Industrial Revolution 4.0, 2019.

[9] M. Awazu, A. Y. Barakat, R. L. Chevaller, and I. Ichikawa, The cause of uremia in obstructed kidneys, vol. 114, 1989.

[10] B. Kawulich, "Qualitative Data Analysis Techniques," Conf. RC33, no. January 2004, pp. 96-113

[11] W. E. Forum, "What does the fourth industrial revolution mean for fashion?," World Econ. Forum, no. November, 2017, pp. 1-18.

[12] "Technology, jobs, and the future of work 2 McKinsey Global Institute."
[13] C. Fadel, G. Lead, and C. Systems, "Prepare Students for 21St Century Skills," no. May, 2008.

[14] S. Kwek, "Innovation in the Classroom: Design Thinking for 21st Century Learning," Stanford Edu, 2011.

[15] H. C. Y. Chan and L. Chan, "Smart Library and Smart Campus," J. Serv. Sci. Manag., vol. 11, no. 06, pp. 543-564, 2018.

[16] K. Soini and J. Dessein, "Culture-Sustainability Relation: Towards a Conceptual Framework," 2016.

[17] Y. Shi et al., "The smart classroom: merging technologies for seamless tele-education," computer.org.

[18] A. Pacheco, P. Cano, A. Flores, E. Trujillo, E. Flores, and P. Marquez, "A Smart Classroom based on Deep Learning and Osmotic IoT Computing Sistemas Inteligentes Difusos View project Pensamiento Computacional View project A Smart Classroom based on Deep Learning and Osmotic IoT Computing," 2018

[19] P. Domingos, "A few useful things to know about machine learning," Commun. ACM, 2012.

[20] A. Durmus and A. Dağll, "Integration of Vocational Schools to Industry 4.0 by Updating Curriculum and Programs," Int. J. Multidiscip. Stud. Innov. Technol., vol. 1, no. 1, pp. 1-3, 2017.

[21] M. Lanz, R. Pieters, and R. Ghabcheloo, "Learning environment for robotics education and industry-academia collaboration," in Procedia Manufacturing, 2019, vol. 31, pp. 79-84.

[22] A. Bahga and V. K. Madisetti, "Blockchain Platform for Industrial Internet of Things," J. Softw. Eng. Appl., vol. 09, no. 10, pp. 533546, Oct. 2016.

[23] M. Turkanović, M. Hölbl, K. Košič, M. Heričko, and A. Kamišalić, "EduCTX: A blockchain-based higher education credit platform," IEEE Access, 2018.

[24] A. Rahmah, "Digital Literacy Learning System for Indonesian Citizen," in Procedia Computer Science, 2015.

[25] Nikita Duggal. 2019." 8 TopTechnology Trends for 2019 and the Jobs They'ill Create". https://www.simplilearn.com/top-technology-trendsand-jobs-article (accessed September 9th 2019)

[26] Priyandharshini. 2019. "Machine Learning: What it is and Why it Matters". https://www.simplilearn.com/what-is-machine-learningand-why-it-matters-article (accessed September 9th 2019)

[27] Eliana Garcia. 2019. The Use of Artificial Intelligence (AI) in Education. https://www.openaccessgovernment.org/artificialintelligence-ai-in-education/66346/ (accessed September 9th 2019)

[28] Nick Walter. 219. Improving Cyber Security in Education. https://www.techradar.com/news/improving-cybersecurity-ineducation-systems"(accessed September 9th 2019)

[29] SAS. Evolution of Machine Learning

.https://www.sas.com/en_id/insights/analytics/machine-learning.html (accessed September 9th 2019) 